\title{
Smart Classroom Technology
}

\author{
Ciaran O'Driscoll \\ Dublin Institute of Technology \\ Ireland
}

\section{Introduction}

This chapter presents a range of technologies and examples of Smart classroom technology prototypes and deployed solutions that have been developed as part of current and recent research activities. The educational rationale for developing and using Smart Classroom Technology is also considered. The potential for an emerging digital divide between students and many educators is reviewed in the context of identifying technologies to support educators. A specific case study in the design and deployment of a cost effective smart classroom that is invisible to the users and based on truly pervasive technologies such as Bluetooth is discussed and evaluated. In the conclusion the potential positive contribution of Smart classroom technology is identified.

\subsection{Smart Classroom Technologies}

A smart classroom is a pseudo intelligent room that can reconfigure itself and its resources automatically based on predefined profiles for specific user groups. This can be done using a predefined schedule or in an event-driven manner based on the arrival of a specific class group and specific lecturer.

Smart classrooms can react automatically to the arrival of staff and students to, for example, set up the space to continue a lecture from a previous session, identify the stakeholders in the room, and record and store material discussed in a session for reflective review. Tedious tasks at the start of, or during, a lecture or laboratory session can be automated, allowing students and lecturers to focus on the learning process. Simple tasks such as providing a list of attendees with associated photographs can enhance the lecturer and student interaction, particularly for large groups or early in the academic term.

Benefits that can be gained from using smart spaces in academic environments are identified. In particular academic institutions can leverage the personal devices of students and staff, in association with standard communications infrastructure, to enable the deployment of smart classrooms in a cost effective manner. For example, the pervasive use of personal mobile phones and PDAs, with significant embedded computing power, provides an opportunity for developing a truly smart environment in a cost-effective manner.

In the case study for a Smart Classroom, based on low cost pervasive technologies is presented, the availability of Bluetooth-enabled personal devices has been used as the core rational for developing the Context Aware Smart Classroom (CASC) within the School of 
Electronic and Communications Engineering (SECE) of DIT. Finally the potential for acceptance of the smart classroom by the key stakeholders, educators, has been investigated through semi-structured interviews and the results presented.

\section{Why Use Smart Classroom Technologies?}

Is there a fundamental educational rational for developing smart classrooms or augmenting existing classrooms? Prior to considering the technical perspective it is a valuable exercise to consider whether there is any educational justification for using smart classroom technologies. In particular can smart classroom technologies fulfill the needs of end-users and stakeholders.

\subsection{Technology and Education}

Learning styles of students are changing as the environment in which we live changes. Traditional lecturing styles require to be reviewed to determine their suitability to meet the needs of student learning styles. Alternative techniques such as problem based learning and peer instruction provide a significant additional burden on educators during the education session. Enhanced or smart classrooms have the potential to significantly reduce this burden.

As the world around us changes it is essential that educators review their teaching methods to ensure there is an appropriate match to students learning styles. In this section two specific teaching methods are considered and the need to address the digital divide between educators and students is discussed.

\subsection{Learning Paradigm Shift}

From an educational perspective learning methods and practises are evolving and improving. Traditional deductive approaches that start with the fundamentals in a formal lecture setting and then move onto applications may not address all learning styles of students. Traditional lecturing clearly identifies to students what is required to be known for exam purposes, while this appeals to many students it is not necessarily the best or most appropriate learning style for all students or all subject material. The appropriateness of traditional lecture style teaching, particularly in engineering and physics, has been under challenge for a significant period. Felder and Silverman (Felder and Silverman 1988) developed a comparison of the styles of learning and teaching that identified an incompatibility between students and educators. These incompatibilities require educators to consider alternative teaching approaches such as problem based learning.

\subsubsection{Problem Based Learning}

Felder (Felder 2002) states that in his experience

"the "best" method of teaching-at least below the graduate school level-is induction, whether it be called problem-based learning, discovery learning, inquiry learning, or some variation on those themes".

Problem based learning involves organizing groups of students to complete a project, or solve a problem, through their own existing knowledge and use research to learn additional material. Educators provide support and guidance to the project groups as required. While 
this requires additional planning and takes more time the students individual learning styles can be more easily addressed leading to more concrete grasp of the material on completion of the project (Felder and Silverman 1988). While problem based learning requires a significant level of preparatory work by educators (Markham, Mergendoller et al. 2003) it is very practically focused and is accepted as appropriate for many engineering and physics subjects.

There are however fundamental concepts that need to be introduced in a more formal lecturing style, though here it is possible to use Peer Instruction rather than traditional lecturing.

\subsubsection{Peer Instruction}

Traditional classroom discussion can also use alternative methods such as peer instruction. Peer Instruction is where questions are interspersed through the lecture to reveal common misunderstandings and also to get students to actively engage in the subject material (Mazur 1997). Educators break the lecture into short presentations that focus on a central point, which are each followed by the conceptual questions. Students are asked a conceptual question and they all provide their initial responses, which are noted. Students are then encouraged to work in small groups to discuss their answers and misunderstandings can be addressed through this peer interaction. After some time the concept under review can be posed to the class, though often in a different form, and the responses noted.

This structured questioning method has been found to give significant learning gains with a high level of acceptance among educators who have tried the techniques (Fagen, Crouch et al. 2002). Crouch (Crouch and Mazur 2001) provide a statistical analysis of 10 years of research using Peer Instruction that found a significant improvement in student understanding and that the effort from educators to motivate the students were greeted positively by the students.

There is growing support for such approaches in order to engage students in an active manner in class sessions. There is a perceived difficulty in getting students to be attentive for the time period of an education session.

\subsection{Digital Divide between Educators and Students}

This is a further driving force in first world developed countries as children get used to immediate gratification through gaming and television that has reduced interest in reading (Prensky 2001a). There is a digital divide that exists between children, who are growing up in a very technologically advanced world, and older people who have not grown up surrounded by the current technologies. Prensky (Prensky 2001a) defines the term Digital Native for students who have been surrounded all their life by digital technology. As a result they are fully conversant with concepts of the internet, hyper text mark-up language (html), mobile phones, multi-media technologies from audio MP3 to digital photography and digital videoing for use on uTube. These digital natives spend more time playing computer games on their televisions using game consoles or with portable game consoles then they spend reading. In this digital habitat the natives are looking for immediate response and interactivity and this has produced a different mind set and way of thinking (Prensky 2001b). Prensky further suggests that the methods used for teaching of the "basics" is legacy teaching and focuses on old teaching rather then teaching for the future. 
Educators who have not grown up in such a digital environment are generally able to use and understand digital technologies however it is like a second language as opposed to a native language and these people are referred to as Digital Immigrants (Prensky 2001a). This creates a language barrier, a digital divide, between Digital Natives and Digital Immigrants that cannot be ignored and requires to be considered by educators.

\subsubsection{Education for Digital Natives}

In order to address the requirements and needs of Digital Natives for immediate response and interactivity Prensky (Prensky 2001a) advocates the use of games for presenting knowledge. Though he accepts educational games or "Edutainment" is at an early stage of development and requires further development. Significant levels of additional resources, such as editors, media and scripting experts, etc. and associated costs are required in the move to edutainment. There is reluctance on the part of many educators to become performers to keep students entertained.

Prensky (Prensky 2008) in responding to critiques of his approach identifies that there is a difference between teaching the "basics", which remain the same, and the best practises for teaching, which evolve over time.

As an example he identifies the difference between the "basic" need to know the time and the evolution of methods for telling time:

"telling time is a "basic." At one time the best method we had was the sundial. Now we all just strap a machine to our wrist".

While Prensky accepts that technology does fail on occasions, he questions the value in providing what he calls "backup" teaching as the main education mode (Prensky 2008). Alternative methods and approaches are needed to focus on teaching for the future to entice and excite students who are Digital Natives. However the value and need to convert education materials into a games format in order to interact effectively with Digital natives has yet to be fully vindicated.

Clearly there is a digital divide that needs to be considered and addressed. The author proposes that this can be done through use of alternative learning paradigms with appropriate technological support.

\subsection{Interactive Classroom Technologies}

There are a significant number of technologies that are available to augment or enhance an existing classroom space. These technologies can be used as components of a smart classroom. In this section the focus will be on technologies identified from literature and from primary research interviews carried out with educational professionals in Ireland.

\subsubsection{Interactive Whiteboards}

Interactive whiteboards such as from SMART technologies (SMARTBoard 2009) or Promethean (Promethean 2009) are widely used in education in Ireland. Interactive boards use a projector to display material on the board that is generated on a computer. The boards are touch sensitive and can be used as a direct input mechanism for a computer. It is possible to select icons or draw directly onto the board and to store the resultant display. 


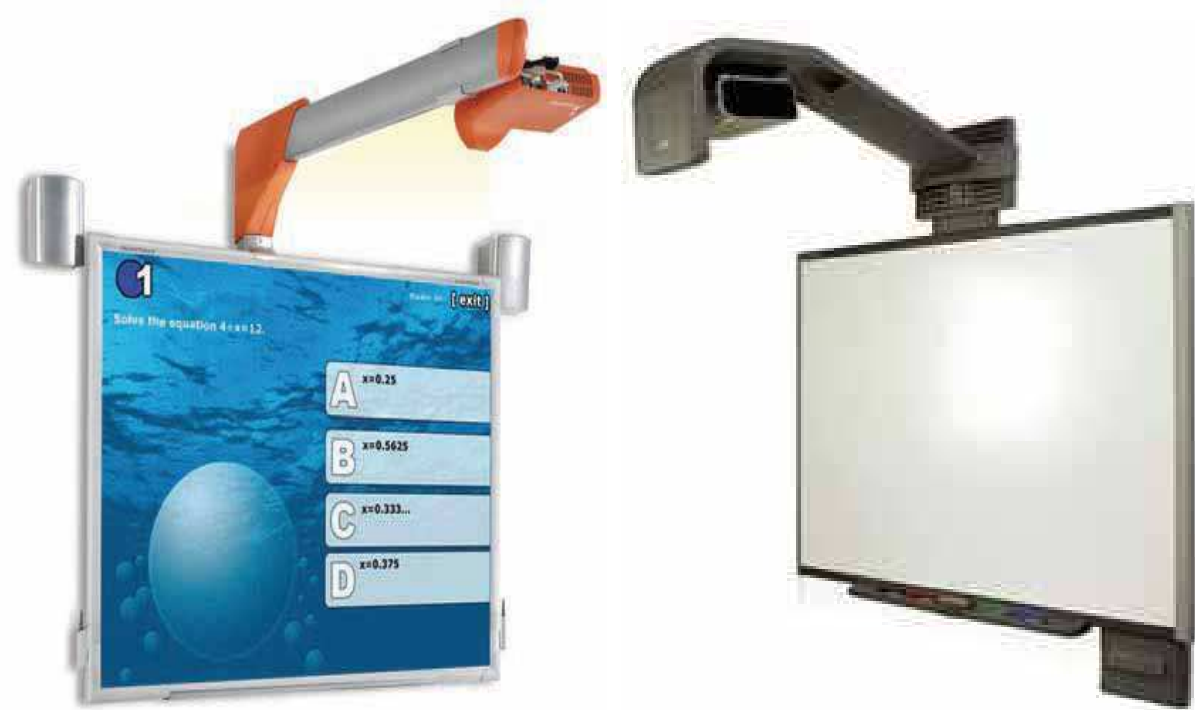

Fig. 1. Fixed Projection Interactive Boards (Promethean 2009) and (SMARTBoard 2009)

In Ireland many primary school level students, ages 5 to 13 , have interactive whiteboards. Educators have found them to be an invaluable resource for teaching children. In particular it provides a rich learning environment that is used to channel the creativity of children in a computer medium. It allows different learning styles to be addressed, visualisation, auditory and touch senses to be used in the classroom (Roche 2009). The cost of acquiring and fitting boards is around $€ 5000$ per classroom and this cost is covered through fund raising activities of parents and not directly from the Government.

In third level Universities and colleges in Ireland there is a slow uptake in using interactive whiteboards. As in the case of the Dublin Institute of Technology, there are less than ten interactive boards across the campuses of the college, though currently in 2009, there are plans to configure specific classrooms with interactive whiteboards (Harvey 2009).

Interactive whiteboards provide an ideal environment for problem based learning, where each student group can use the board to prepare presentation material or share ideas during the process and later to have an electronic record of the discussions (Bowe 2009).

\subsubsection{Interactive Response Systems}

Interactive Response systems or voting systems, such as from Quizdom (Quizdom 2009), can be used in the classroom to permit students to respond to questions posed by the lecturer. Each student has a handheld device that can be used for selecting one of a specific number of predefined answers. Each student has an independent remote unit that operate using wireless signals, infra red versions do exist but these require line of sight between transmitter and receiver. It is also possible to implement a classroom response system using existing mobile phones and additional software, though these systems use SMS and there is an associated on-going usage cost. 
These are not widely used in the Irish education system, for example in the Dublin Institute of Technology there is currently one set of 60 remote devices that are shared among a number of lecturers who are actively using Peer Instruction techniques (Bowe 2009).

Interactive response systems are ideally suited for Peer Instruction. Student responses are automatically collected and collated and can be displayed in a histogram or tabulated format. In many cases the initial responses are used only by the lecturer to assist in directing the discussions and not displayed to the class group. The supporting software for these interactive voting systems allows educators to readily develop questions and maintain response statistics over an academic period. In particular responses can be exported into the Learning Management System, WebCourses, used in the Dublin Institute of Technology (Bowe 2009).

\subsubsection{Capture Systems}

Capture systems collect the activities of the classroom environment and store them for later review, either by students or educators. Using display systems such as interactive whiteboards permits the capturing of material presented, modified or generated on a display in electronic format. Audio recording can supplement the captured information, though a time indexing mechanism is required to ensure the material and the audio are synchronised during review. Video recording using single or multiple cameras provides a significant quantity of material for review that also requires careful synchronisation with audio or display information.

The complexity in capturing systems is increased where there is a need for post-processing where educators may require the option to edit audio or video material. These systems shall be discussed in more detail in the Smart classroom section of this chapter.

\subsubsection{Interactive Classroom Technologies}

Interactive classroom technologies provide an ideal opportunity to enhance the learning environment for students and provide support for alternative learning paradigms to assist educators address the digital divide. Interactive Classrooms provide the capability for users to use technology as a tool to support different learning paradigms, such as peer instruction and problem based learning. This provides a clear educational rationale, with appropriate learning paradigms and suitable technologies, to justify the development of interactive or smart classroom.

Smart Classrooms, in simple terms, are interactive classrooms that provide an additional level of automated response based on the specific situation and are a subset of Smart Spaces.

\section{Smart Spaces}

Smart spaces are an extension of the Ubiquitous Computing paradigm. The core concept in Ubiquitous Computing is the ability of the technology to disappear and become invisible to users (Russell, Streitz et al. 2005; Streitz and Nixon 2005). In the ubiquitous computing paradigm, if a computer:

"knows merely what room it is in, it can adapt its behaviour in significant ways without requiring even a hint of artificial intelligence" (Weiser 1991). 
Smart environments display a degree of autonomy and can adapt to changing situations and communicate with users (Das, Cook et al. 2002). The provision of intelligence based automation enhances ubiquitous computing environments and provides the opportunity for additional features such as detection of anomalous behaviour. Devices can easily be controlled using existing communications infrastructures based on sensor information collected and in particular predictive decision making can be included in the capabilities of the smart environment (Das and Cook 2006). These capabilities allow an environment to exhibit pseudo-intelligent behaviour and so be considered as a smart environment.

Through the collection of relevant data a smart environment is context aware and can use context to inform it's decision process.

\subsection{Context Aware Computing}

"Context-aware computing is a mobile computing paradigm in which applications can discover and take advantage of contextual information such as user location, time of day, nearby people and devices and user activity" (Chen and Kotz 2000).

This concept has been around for over a decade and it is only the recent availability of suitable portable computing and wireless network resources that make it possible to implement such systems. In the case of smart classrooms the interactive technologies provided significant enhanement capabilities.

The term context is used to describe real world situations, and everything is said to happen in a certain context. This makes it difficult to define context in a precise manner for many different situations. In computing the term "context-aware" was introduced in (Schilit and Theimer 1994) and was applied to location information that could enable software to adapt according to its location of use, the identities of nearby people and objects, and changes to those objects over time.

\subsection{Location Aware Computing}

Many context aware applications focus on location and these are described as locationaware computing applications (Schilit, Adams et al. 1994; Want, Hopper et al. 1992). A key consideration in location-aware computing is the degree of accuracy required for a particular application and the accuracy that the technology can provide. Many situations do not require a high degree of accuracy such as with "locating a friend" solutions based on who is in a GSM cell. In the case of American legislation governing the location of a person making a 911 call, the requirement for positional accuracy of mobile phone systems is to be better than 50 meters for $67 \%$ of calls made (released October 6, 1999). This directive encouraged many mobile phone designers to considering the inclusion of GPS chipsets into their handsets.

There are many location-aware or location based applications such as museum guides (Hsi 2002) and tourist guides (Long, Aust et al. 1996). In these applications a variety of mobile and static technologies have been used to support the provision of environments that respond to users according to their location context. In these systems users choose voluntarily to use the system to get additional information. 


\subsection{Location and Data Privacy}

In developing smart environments, due regard to individuals' privacy is required to be considered. The ability to identify and track the location of specific individuals is covered by EU regulations and cannot be ignored. The collection of electronic location data requires to be protected under the EU data protection directive (1995). Article 6 of the directive demands that:

"personally identifiable data are only collected for explicit and legitimate purposes, it must be accurate and up to date or else erased, it must be relevant and not excessive with respect to the purpose of collection and it must be stored for as long as necessary for the purposes for which the data was collected."

Article 7 of the directive also requires "explicit consent or demonstration of necessity" to collect the data.

The preferred approach would be to have students opt-in to using the system and to permit tracking of their location for the purpose of providing enhanced services. Students would get up to date information, such as room changes and current material by opting into the system. Provision of sufficient enhanced services might be enough to encourage them to use the system.

An alternative approach to an opt-in policy is to ensure location data for specific individuals cannot be identified. Anonymity provided by use of pseudonyms could be used to ensure locations and identities are not correlated. This approach is not entirely secure, as when only a few individuals are within an area an observer may be able to identify individuals and their respective pseudonyms (Beresford 2005). This alternative approach provides users with a degree of anonymity; however at some level the system would require to identity individuals in order to provide appropriate services and this would always be a point of concern.

\subsection{Context Awareness}

Location is an essential element in defining context but it is by no means the only aspect that needs to be considered. Context in computing terms involves a number of different aspects as identified in (Schilit, Adams et al. 1994) a definition for context with 3 elements is presented:

Computing context, made up of nearby computing resources, communications and communications bandwidth.

User context, such as the user's profile, location, people nearby and even the social situation. Physical context, such as lighting noise levels, traffic conditions and temperature.

To more completely define context for computing time was proposed as a fourth element in (Chen and Kotz 2000):

Time context, where user and physical contexts can be logged to provide a context history that can be useful in certain applications.

These four particular aspects provide sufficient definition of context for the design and development of the context aware smart spaces. Context can be further categorised based on the specific situations under consideration.

\subsection{Categories of Context}

There are a number of categories of context such as environment, time, temperature or user identity. Location and identity are used to enable software to adapt to the people and objects 
that are nearby and to objects that change over time (Schilit and Theimer 1994). In a similar manner, where and who one is, and what resources are available nearby, along with the social situation can be considered as in (Schilit, Adams et al. 1994).

A suitable set of primary categories that coincide with the earlier definition of context are identified in (Dey and Abowd 1999):

"Identity: the identity of the relevant entities.

Location: the geographical position of relevant entities.

Activity: the activity or activities being performed.

Time: The period at which the entities perform the activity."

The category 'activity' is introduced as opposed to 'environment' on the basis that the word environment is used as a synonym for context.

These four primary types are sufficient to fully categorise a specific context, such as the temperature of a location at a particular time. These primary types can also be used as an index to determine secondary information, such as a phone number, which can be determined from the identity of an individual then be used as an index to a phone book. Context data is an essential element for smart classroom enviroenments.

\subsection{Smart Classroom Environments}

Smart classrooms are specific cases of Smart Spaces in which sensors collect context data that can be used by a decision engine, in association with rules, to reconfigure the environment.

\section{Smart Classrooms}

There are many types of Smart Classroom that exhibit varying levels of pseudo intelligence to changing the behaviour or configuration of an environment based on decisions related to users, resources and preset rules or policies.

\subsection{Classroom 2000 and eCLass}

Classroom 2000 (Abowd 1999), renamed as eClass (Brotherton and Abowd 2002), was designed specifically for capturing, through audio and video recording, material presented at a lecture event for later review by students. Multimedia captured material was used to enhance existing class material and web enhanced material to provide a richer review experience. This system involved the development of post-editing facilities to permit lecturers to have comments or sections of the lecture removed prior to distribution via internet access. Lecturers entering the lecture spaces required to log on to the system in order to initiate the capture system (Brotherton and Abowd 2002).

eClass was in use for a period of 3 years and was assessed extensively over that period. An extensive report indicated that access to the recorded material went up significantly before exam times in a repeated manner to indicate general acceptance and use by students. Attendance was not dramatically affected by use of the system. However at under graduate level students did indicate it might cause them to miss more lectures on an occasional basis, while at graduate level where lectures are more discussion based students indicated their attendance was not affected. There was significant positive feedback from students that 
used the system however there was no overall statistical improvement on students results during the period of the study (Brotherton and Abowd 2004).

\subsection{National Institute of Standards and Technology Smart Space Project}

The information access of the National Institute of Standards and Technology, NIST, are interested in developing standards and measurement techniques to address interoperability challenges for pervasive environments that use vast amounts of sensor data. This requires a demonstrator environment that uses pervasive sensors and networks to sense activity and to react appropriately. Current NIST research focuses on a meeting room data collection environment that has multiple cameras and microphone arrays which generate significant volumes of data that have to be handled across networks in this distributed scenario (NIST 2009). An example of the system operation is shown in figure 2 below with multiple camera views and microphone level indicators across the bottom.

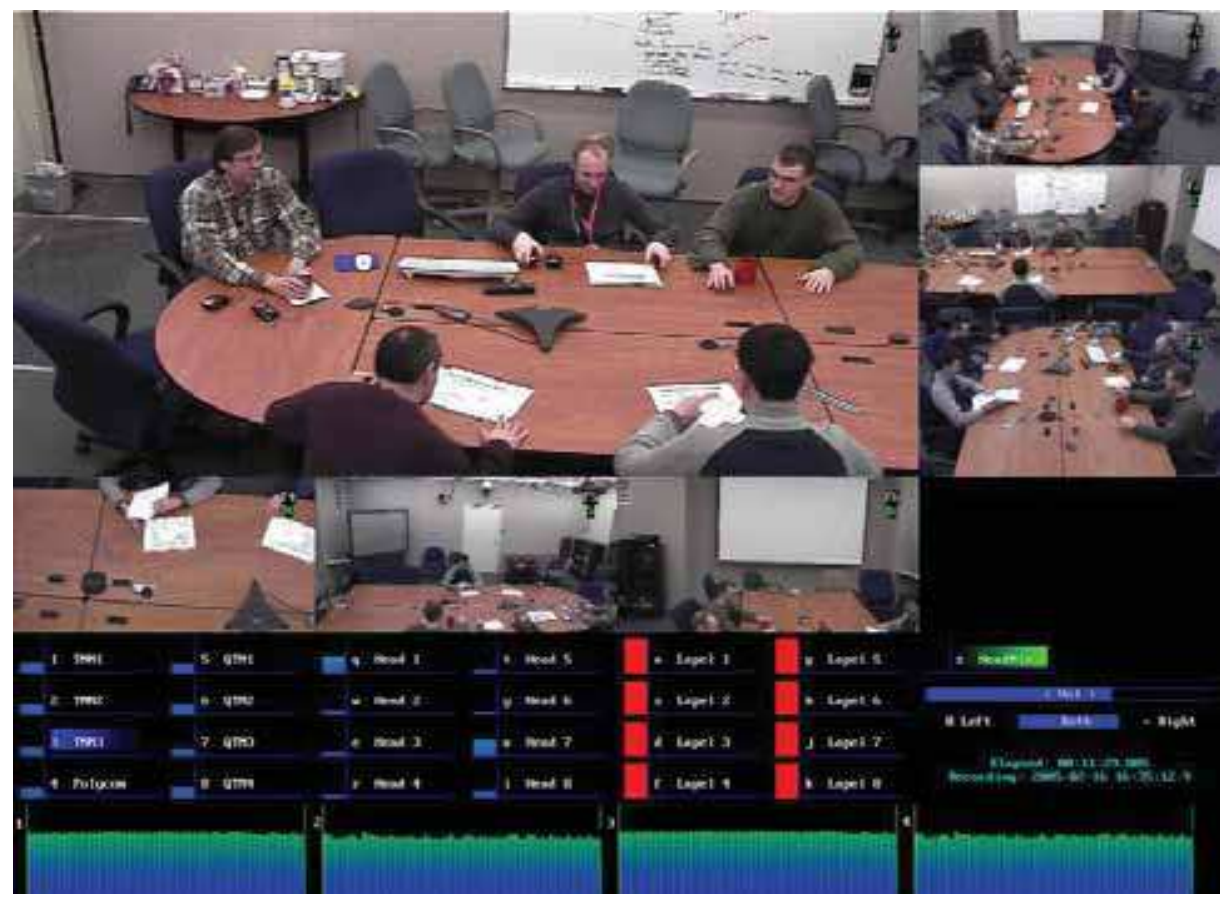

Fig. 2. NIST Meeting Room Data Collection Laboratory (NIST 2009)

This NIST project is a capture based environment and while it is not explicitly a smart classroom implementation it is widely referenced and has been used as the basis of alternative smart space projects.

\subsection{Tsinghua Smart Classroom for Tele-Education}

This project based in the Chinese university of Tsinghua integrates a significant level of technology to provide remote users with an experience close to a real classroom 
environment. A smart media board is used for the display with a speech recognition system to provide a virtual assistant and to mange the cameras there is a smart camera man that decides which camera to use based on activities in the space. Remote students are projected onto the side wall in order to be able to participate in the lecture. Lecturers are required to login to the system using biometrics based on facial recognition and speaker verification (Shi, Xie et al. 2003).

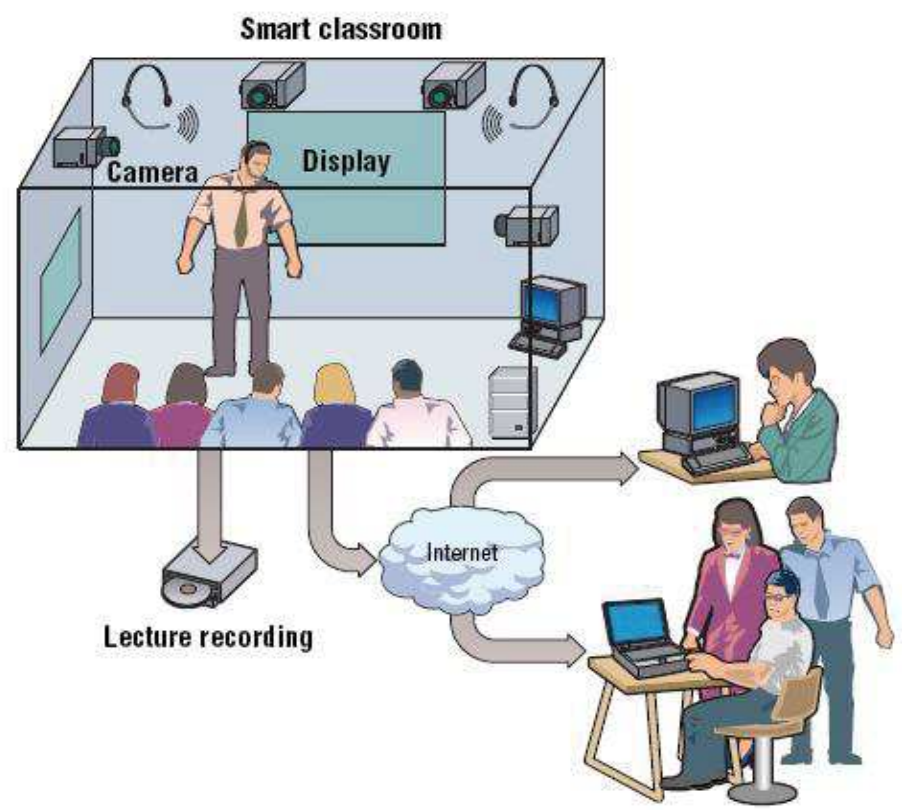

Fig. 3. Tsinghua Smart Classroom (Shi, Xie et al. 2003)

Similar to the NIST project it is a capture based system. This classroom is highly instrumented with a significant variety of technologies being integrated to provide an enhanced remote learning experience.

\subsection{Open Smart Classroom}

This prototype system was also developed in Tsinghua and used to support interaction between Chinese and Japanese universities. Similar in facilities to the Tsinghua Smart Classroom it provides support for intercultural exchanges through machine translation of information presented on the Langrid blackboard (Suo, Miyata et al. 2008).

"The two classrooms are connected through the internet with live video shared in both classrooms. The original presentation is in English and translated presentations (in Chinese and Japanese) are showed synchronously in the respective locations.

1) Touch-sensitive SmartBoard screen, displaying presentation for the class; 2) Live video of Kyoto, 3) Support tools helping the students to communicate with each other in different languages, and also giving feedback and questions to the teacher; 4) On-line Chinese translated presentation; 5) The teacher, giving a class in Tsinghua; 6) The Chinese students, using aided tools for discussion. 7) 
Presentation of the class material, 8) Live video of Tsinghua University, 9) On-line Japanese translated presentation, 10) The Japanese students, using the support tools for discussion" (Suo, Miyata et al. 2008).

\section{Open Smart Classroom in Tsinghua}

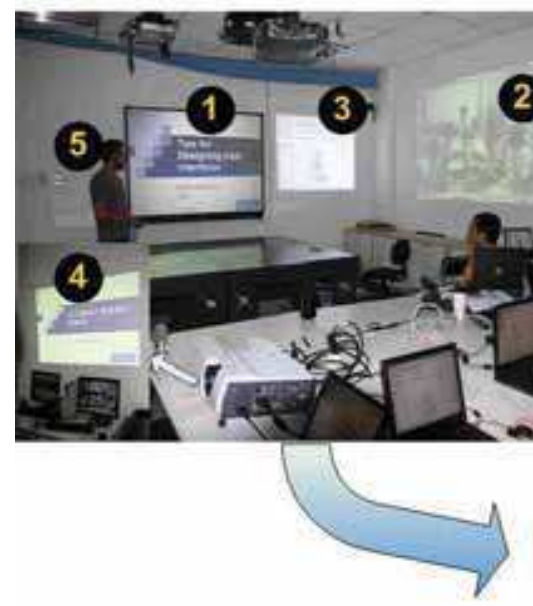

Open Smart Classroom in Kyoto
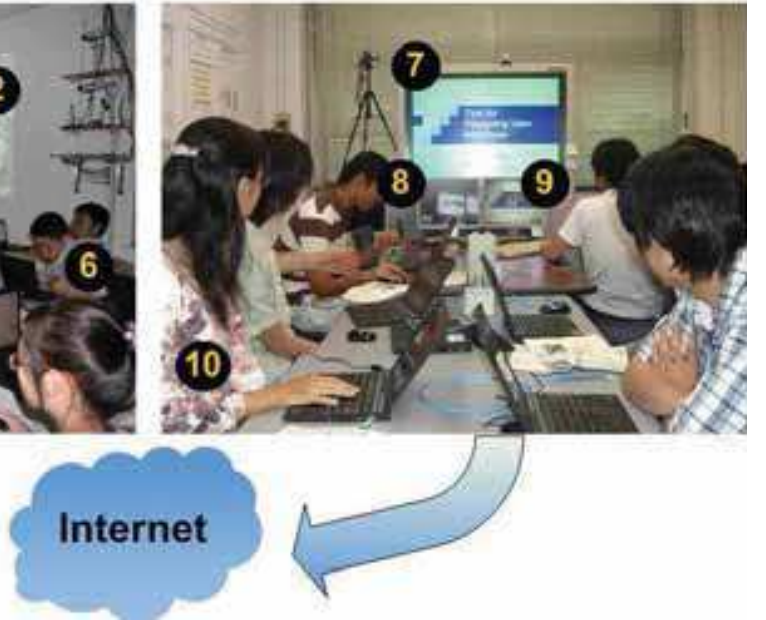

Fig. 4. Open Smart Classrooms systems: Two classrooms in Tsinghua and Kyoto (Suo, Miyata et al. 2008)

As an example of the potential for highly distributed and intercultural support using translation techniques, it will be interesting to see if this prototype can be deployed in a real environment in the future. The level of instrumentation required and the potential issues for network bandwidth makes real world deployment an interesting challenge.

\subsection{Network EducationWare}

Network EducationWare, NEW, is interesting as it focuses on providing an inexpensive solution to support Smart classrooms and distance learning. In particular is the approach to conserving bandwidth usage to support remote access over low bit rate modems, $56 \mathrm{~kb} / \mathrm{s}$. An interactive white board is used for presentations and annotation, and presentations are converted into PDF format to minimise bandwidth. In the situation that a video or high bandwidth multimedia is to be used during a lecture this requires to be downloaded in advance of the lecture session. Privacy is considered in the system as questions to the lecturer are not visible to all students. This requires the lecturer to restate the question if it is of interest to the class group. This has been in use for three years and claims a student community of 2500(Snow, Pullen et al. 2005). 


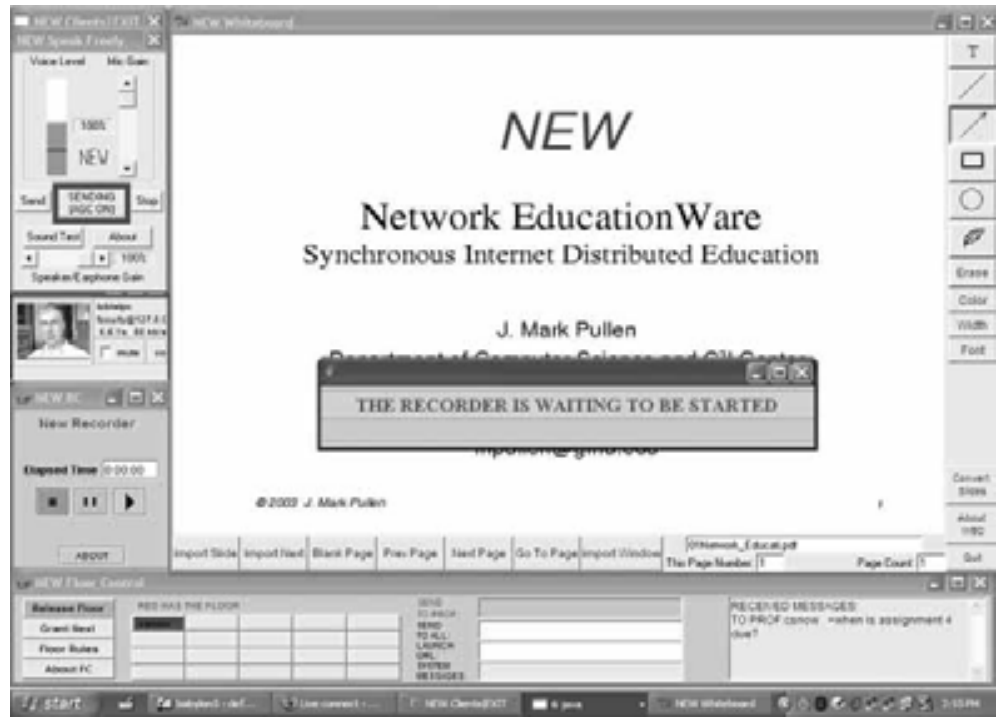

Fig. 5. NEW User Interface (Snow, Pullen et al. 2005)

As a capture system this approach does not require a highly instrumented environment with high cost infrastructure. It permits inexpensive and truly available devices and network infrastructure to be used to deliver an enhanced learning environment to remote users. This system is also available for use under an academic open-source license.

\subsection{Ubiquitous Smart Classrooms}

Weiser's (Weiser 1991) and Russell's (Russell, Streitz et al. 2005) concepts of ubiquitous computing focuses on the use of devices that become pervasive or technologies that can disappear into the background. In Weiser's vision environments will have sensors for regular operational needs and the development of "applications are of course the whole point of ubiquitous computing" (Weiser 1993). In this context the use of highly instrumented spaces that require post-processing or significant computing facilities reduces the potential for the deployment of applications in real world scenarios.

It is from the perspective of developing a smart classroom using currently pervasive devices, with the limitations of existing network capacities that the Context Aware Smart Classroom was designed.

\section{Context Aware Smart Classroom: A Case Study}

CASC focussed on making, real-time, context aware decisions based on information collected from the environment sensors, policies and rules of the smart classroom for the dissemination of material over WLAN, LAN or email during a class period.

This case study discusses the design and implementation of a Context Aware Smart Classroom, CASC, that focuses on leveraging existing pervasive technologies and infrastructures 


\subsection{Leveraging Existing Infrastructure}

Current education environments, particularly at University level, referred to as third level education in Ireland, support modern Information Technology, IT, infrastructures that can be utilised as a basis for developing smart classrooms. Current IT infrastructures permit rooms and spaces to be used for a variety of different purposes from standard lectures using projectors, to tutorials and practical computer based activities.

The pervasive nature of personal mobile devices permits the investigation of developing low-cost location and identification systems that support development of a smart classroom. Material used during the teaching activity is distributed to students based on students' policies using WLAN, LAN or email. CASC uses the exisiting central scheduling system to determine the teaching activity.

\subsection{System Design}

Context Aware Smart Classroom, CASC, was designed to react to changes in the environment according to rules preset in the system. A rules algorithm was designed to check information stored in local database tables and makes decisions based on current system context and preset policies. The prototype system implements two main rules:

What should happen when lecturer enters the room?

Which student should the notes transfer to and how?

Delivery of material presented and developed in the lecture session is the initial aim of the prototype system. A block diagram of the key components of CASC is shown in Figure 6.

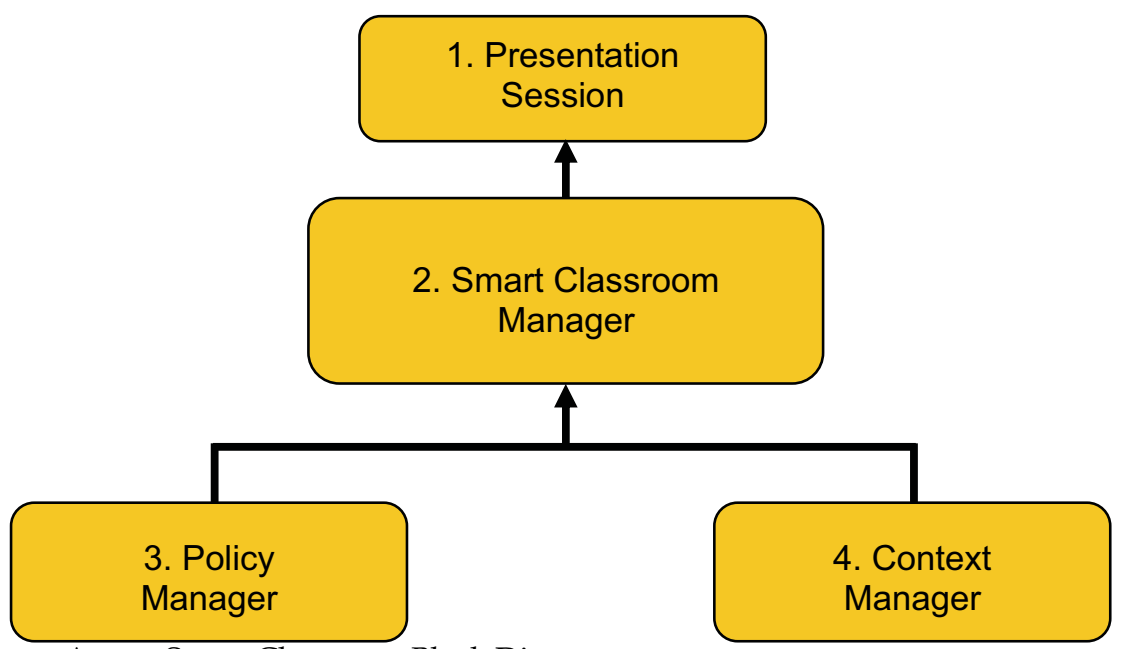

Fig. 6. Context Aware Smart Classroom Block Diagram

\subsubsection{Presentation Session}

The presentation session component is a client that resides on a local PC in the smart classroom that is responsible for locating the appropriate PowerPoint file and displaying it, starting at the appropriate slide. 


\subsubsection{Smart Classroom Manager}

The core of the CASC system is the smart classroom manager that provides the adaptive behaviour based on a set of system rules. The manager collects the policy settings of the users and the current context by connecting to appropriate database tables and is responsible for transferring material to students according to student specific policies.

\subsubsection{Policy Manager}

Students and lecturers can log into the system and modify their policies based on the set of options presented. The room operation is set by a room policy that can be modified by the lecturer and the CASC administrator. The notes policy is set by the lecturer and can be used to initiate a change of venue to ensure that appropriate facilities are available in a room.

Lecturer's policy: This policy can request advance notification of lecture times and venues, which is mainly required if room venues are dynamically allocated. The policy informs the CASC client where to access notes, either from the lecturers' desktop machine, wirelessly from a PDA or a central server and they are then displayed on the room projector. The lecturer can set the distribution of material to those present or to all students of the class group.

Students' policy: This policy enables the student to specify how the lecture material is to be transmitted, such as wirelessly to a laptop in the room, or sent to an email address. Also, this policy enables the student to remotely access the smart classroom and receive notes.

Room Policy: The room policy allows the smart classroom to be used for a range of purposes such as a lecture, tutorial, or presentation. Based on the room policy being set as presentation a particular student may take on the role of the lecturer. The room policy ensures the correct activity, such as lecturer and student group, takes place the appropriate room at the right time and date. CASC can send a message to lecturers or students who enter an incorrect room.

Notes Policy: Certain lecture notes may require audio or DVD players and these options can be set by the lecturer. However a room with the appropriate functionality must be requested in advance of the lecture period. This permits the system to find a suitable room and give advance notice to students and the lecturer which room is available. A lecturer can set the notes policy to specify who receives the notes for each of the cases: when a student is present physically in the room; remotely signed in; or not present.

\subsubsection{Context Manager}

The context manager is responsible for collecting real-time data and storing the information into appropriate tables in a database for use by the smart classroom manager. The context manager relies on a Bluetooth monitoring daemon on the local computer for communicating with user devices.

Identity: Users are identified through the MAC address of their personal devices. When users are added to the system specific device configuration information is also required to be added.

Location: There are two location elements in the system, the smart classroom location and the location and tracking of individuals. The location of individuals is identified using the Bluetooth enabled personal devices and requires to determine if the user is inside the room. 
It is possible for CASC to change the room location and generate a Bluetooth broadcast to the appropriate student and lecturer that the venue has changed.

Activity: An academic activity or event is defined in the central scheduling system database and requires a lecturer, class group, venue and activity such as a lecture or tutorial to be identified. The context manager connects to the central database and copies relevant schedules to a local database table for access by the smart classroom manager.

Time: The start time of each activity and the duration is determined from the central scheduling system. This can be used by the smart classroom manager to send out reminders using Bluetooth or email to lecturers and staff in advance of lectures.

\subsection{CASC Implementation}

In order to provide a scalable solution a client-server architecture was implemented. Each smart classroom requires a local client that manages the classroom space. This client is used to access the Bluetooth device for identification of students and lecturers. Lecture material such as slides and classroom material are managed by the server.

Privacy issues are addressed by having students and lecturers opt-in by registering their own Bluetooth devices and configuring their personal preferences which are used to create profiles for the decision engine. A MySQL database is used on the server to store device, personal information and room configurations. Scheduling information from the central management Information system is transferred into the MySQL database when required by the servers decision engine.

\subsection{Managing the Classroom}

The local classroom PC is used to run the CASC client, which is responsible for scanning for Bluetooth devices and for retrieving the presentation material for the lecturer. The scanning routine runs continuously and commences a scan every 30 seconds that will identify all Bluetooth devices in the neighbourhood and pass any information collected to the CASC server for the smart classroom manager.

A classroom manager determines if a lecturing event is to take place and updates the client on the current status for the particular room such as no class scheduled. On the arrival of a user, acting in the lecturer role, at the appropriate time the classroom manager will welcome the lecturer, retrieve the appropriate material and present the lecturer with options to commence from a specific slide, change to a different lecturer session or finish the session.

\subsection{System Deployment}

CASC was deployed in a laboratory in the School of Electronics and Communications Engineering (SECE) at DIT as shown in Figure 7. Currently in SECE, lecture theatres are equipped with LCD projectors and computers connected to the network to enable presentation of material and so CASC can easily be deployed in lecture theatres.

The CASC system uses commonly available personal mobile devices supported by pervasive technologies such as Bluetooth, WLAN and LAN that make system deployment relatively simple and cheap to deploy in a real academic environment. The system is a client-server architecture that makes it easier to set up many smart rooms by adding the CASC client and a Bluetooth dongle to existing theatre or lecture facilities. User interaction is quite straightforward, using applets to setup database tables, although users are required 
to find the Bluetooth MAC address of their personal mobile devices. The CASC system effectively managed the retrieval, display and distribution of presentation material as intended.

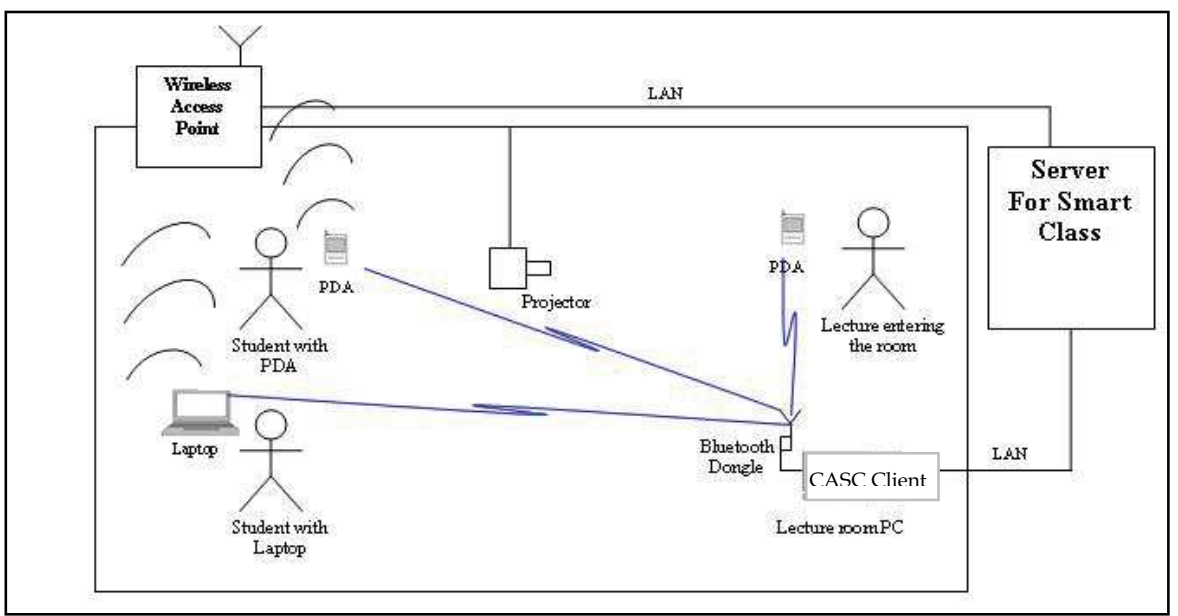

Fig. 7. Context Aware Smart Classroom System configuration

\subsection{CASC Limitations}

The Bluetooth sensor occasionally scanned extra devices that were not inside the room. This problem depended on the actual positioning of the Bluetooth monitoring sensor. In the case of the local PC being positioned near the door Bluetooth devices outside of the room can be scanned. In this case a student identified as a member of the group would receive the material without attending the session. In the case that the PC was located at an external wall, away from the door, devices outside of the room were not identified by the system.

Performance issues, in terms of system response time, were identified in identifying and transferring material to students when the number of devices in the room was increased. This was due to the time required for Bluetooth to scan the room and collect each devices MAC address, this was observed to take about 5 seconds per device to scan and identify the user.

\subsection{Evaluation}

Part of the evaluation process is to determine whether users are willing to use the system. Initial feedback from students has been positive and location privacy concerns in relation to system usage have proved to be unwarranted from the student's perspective. In informal discussions students indicated limited concern regarding privacy of their location or data. While research supports this attitude such as Beckwith (Beckwith and Mainwaring 2005) identifyng an array of personal information disclosed on the internet in every day life from credit card numbers to personal addresses. Robles (Robles, Sukumaran et al. 2006) points out the unprecedented self-disclosure through participation in personal home pages, webcams and blogs. 
The perceived student perspective requires to be considered in a more formal evaluation approach to determine if it will effect student engagement with the system.

\subsubsection{Educator Interviews}

Educators require to accept and engage with the proposed solution in order to ensure the technology is fully utilised.

\begin{tabular}{|c|c|c|}
\hline Interviewee & Role & Interview Key Points \\
\hline $\begin{array}{l}\text { J. Kellegher } \\
\text { (Kellegher } \\
\text { 2009) }\end{array}$ & Lecturer & $\begin{array}{l}\text { Practical laboratories are multi-functional and there is often a delay } \\
\text { in starting the sessions. } \\
\text { Simplify tedious tasks at the start of practical sessions, such as } \\
\text { setting up appropriate applications on student computers. } \\
\text { Pre-load laboratory material to individual machines and pre- } \\
\text { configure machines. Pre-load lecture material. }\end{array}$ \\
\hline $\begin{array}{l}\text { D. Clarke } \\
\text { (Clarke 2009) }\end{array}$ & Lecturer & $\begin{array}{l}\text { Provide support for peer instruction in classrooms. } \\
\text { Display student photographs and names on a lecturer display to } \\
\text { assist student interaction, particularly at the start of a semester. } \\
\text { Consider voice to text for capturing material discussed in lecture. }\end{array}$ \\
\hline $\begin{array}{l}\text { D. Gordon } \\
\text { (Gordon 2009) }\end{array}$ & Lecturer & $\begin{array}{l}\text { Use the technology to change the habitat for the students who are } \\
\text { digital natives. Provide option for peer feedback and peer } \\
\text { instruction. Consider accessibility issues, provide auto note taking } \\
\text { for students with dyslexia or poor eye sight, text to voice, Also of } \\
\text { value to non-native English speakers. } \\
\text { Provide management layer to abstract lecturer from the technology }\end{array}$ \\
\hline $\begin{array}{l}\text { P. Doyle } \\
\text { (Doyle 2009) }\end{array}$ & Lecturer & $\begin{array}{l}\text { Consider providing Pod casts, synchronised with material } \\
\text { presented and developed during the lecture } \\
\text { Limit the capabilities of the system to match available and } \\
\text { pervasive technologies. }\end{array}$ \\
\hline $\begin{array}{l}\text { B. Bowe } \\
\text { (Bowe 2009) }\end{array}$ & $\begin{array}{l}\text { Learning \& } \\
\text { Teaching }\end{array}$ & $\begin{array}{l}\text { Focus on student centred learning approaches, such as peer } \\
\text { instruction and problem based learning as they have been } \\
\text { successfully implemented. Integrate solution with the learning } \\
\text { Management System, WebCourses. Identify suitable interactive } \\
\text { response systems to integrate with room, aim to engage and reduce } \\
\text { passive listening. }\end{array}$ \\
\hline $\begin{array}{l}\text { J. Harvey } \\
\text { (Harvey 2009) }\end{array}$ & $\begin{array}{l}\text { Learning \& } \\
\text { Teaching }\end{array}$ & $\begin{array}{l}\text { Interactive classrooms spaces to be deployed with interactive white } \\
\text { boards and integrated response system, however only limited } \\
\text { number possible. } \\
\text { Consider non formal learning spaces with technology support for } \\
\text { students outside the classroom. }\end{array}$ \\
\hline
\end{tabular}

Table 1. Summary of Interviews Regarding Smart and Interactive Classrooms

As identified previously there is an initial learning curve and time consideration when changing lecture styles. To ensure the next version of the system meets lecturer requirements a number of lecturers were interviewed, during March 2009, in a semistructured manner to identify the key issues that would encourage system usage. Table 1 summarises the key points in the interviews. 
Many of the key points can readily be addressed with minimal extensions to the system, such as providing student photographs on a separate display. However voice to text conversion is not a truly ubiquitous facility and as such will not be considered in the next development phase. In order to perform a more complete evaluation a longitudinal study is currently being planned.

The purpose of developing the CASC system was to leverage existing technologies such as using the personal devices of students and lecturers as Bluetooth tags; to use the existing communications infrastructure provided by WLAN, LAN and email to enhance the students experience in the classroom. The smart classroom manager has been designed to automatically adapt to the behaviour of the room, based on the context, user policies and the core rules of the system. Bluetooth provided an acceptable solution to identifying users within the room although it occasionally identified users outside the room. The time for Bluetooth to identify each user raises concerns about the potential scalability of this identification technique. An alternative technique such as RFID tags in the student cards would probably improve performance and avoid mistaken identification. The CASC system operated as an effective demonstrator for the use of context awareness as a driver for creating a low-cost smart environment that can be developed using existing infrastructure and personal devices.

\section{Future Work}

Interesting concepts were identified from the primary interviews carried out and these will be evaluated in order to identify which can readily be supported. In particular the concept of pre-configuring machines and pre-loading materials is being considered. To accomplish this, a thin client model is proposed with a single authentication scheme for accessing different operating systems from a single desk-top (Doyle 2008).

Technical limitations of Bluetooth are being addressed by including RFID technologies to address the identification time delays. An interactive response system is being developed that can use mobile phones to permit peer instruction in any classroom.

\section{Conclusion}

Smart classrooms as in the case of eClass provide an interesting technical solution that does not necessarily guarantee improved student learning, based on grades measured (Brotherton and Abowd 2004). It is necessary to support the technology with appropriate learning styles and pedagogies and then assess the appropriateness of the technical solution. There is evidence to support the concept of a Digital Divide developing between students and educators. For example students have expressed limited concern about personal data on the internet while educators tend to be more privacy aware. Students seem to be more passive learners and require more effort from educators to get them to engage using traditional lecturing approaches.

Appropriate learning styles, such as Problem Based Learning and Peer Instruction, have been proven to engage students and also gain measurable improvements in student learning. The difficulty for educators is the additional burden in using these methods in classroom environments with large numbers of students. 
In certain scenarios, such as large lecture spaces with over a hundred students, all learning paradigms will not be suitable, however Interactive Response Systems could be used in such environments. Peer instruction could be used in such cases, permitting groups of 3 to 5 , depending on room configuration, (Limited to 3 in the case of standard lecture theatre with seats organised in a row). The volume of data would be relatively small and could be easily be managed automatically, though there may be time delays due to interference between devices. Smart Classroom technology provides the ability to manage complex environments that contain multiple technologies and pervasive devices.

Smart Classroom technology has the potential to play a supporting role for educators in gaining student engagement and getting measurable gains in student learning and exam performance.

\section{References}

(1995). Data Protection Directive (95/46/ec) (released October 6, 1999). Revision of the Commission's Rules to Ensure Compatibility with Enhanced 911 Emergency Calling Systems, . Third Report and Order.

Abowd, G. D. (1999). Classroom 2000: An Experiment with the Instrumentation of a Living educational Environment IBM Systems Journal Vol. 38, No.(4 ), 508-530.

Beckwith, R. and Mainwaring, S. (2005). Privacy: personal information, threats, and technologies. Proceedings of Technology and Society, 2005. Weapons and Wires: Prevention and Safety in a Time of Fear. ISTAS 2005. Proceedings. 2005 International Symposium on, 9.

Beresford, A. R. (2005). Location Privacy in Ubiquitous Computing. Computer Science, University of Cambridge. Ph.D.

Bowe, B. (2009). Learning paradigms and Interactive Classrooms. Interviewed by. C. O'Driscoll. Dublin Institute of Technology, Ireland. (25th March 2009).

Brotherton, J. and Abowd, G. D. (2002). eClass. Sixth Chapter In: The Digital University: Building a Learning Community. R. Hazemi, S. Hailes and S. Wilbur, Ed. 252, Springer Verlag 185233-478-9.

Brotherton, J. A. and Abowd, G. D. (2004). Lessons learned from eClass: Assessing automated capture and access in the classroom. ACM Transactions ComputerHuman Interaction. Vol. 11, No.(2), 121-155. ACM. 1073-0516.

Chen, G. and Kotz, D. (2000). A survey of Context-Aware Mobile Computing Research. Technical Report Dartmouth College Computer Science.

Clarke, D. (2009). Reviewing Smart Classroom Technologies. Interviewed by. C. O'Driscoll. Dublin Institute of Technology, Ireland. (12th January 2009).

Crouch, C. H. and Mazur, E. (2001). Peer Instruction: Ten years of experience and results. American Journal of Physics Vol. 69, No.(9). September 2001,

Das, S. K., Cook, D. J., Battacharya, A., Heierman, E. O., III and Tze-Yun, L. (2002). The role of prediction algorithms in the MavHome smart home architecture. Wireless Communications, IEEE Vol. 9, No.(6), 77-84.

Das, S. K. and Cook, D. J. (2006). Designing and modeling smart environments. Proceedings of World of Wireless, Mobile and Multimedia Networks. WoWMoM 5 pp. 
Dey, A. K. and Abowd, G. D. (1999). Towards a Better Understanding of Context and Context-Awareness Technical Report Georgia Institute of Technology, College of Computing.

Doyle, P. (2008). Ubiquitous Desktops with Multi-factor Authentication. Third International Conference on Digital Information Management (ICDIM 2008). London.

Doyle, P. (2009). Reviewing Smart Classroom Technologies. Interviewed by. C. O'Driscoll. Dublin Institute of Technology, Ireland. (13th January 2009).

Fagen, A. P., Crouch, C. H. and Mazur, E. (2002). Peer Instruction: Results from a Range of Classrooms. The Physics Teacher Vol. 40, No.(April 2002), 206-209.

Felder, R. M. and Silverman, L. K. (1988). Learning and Teaching Styles In Engineering Education. Journal of Engineering Education Vol. 78, No.(7), 674-681.

Felder, R. M. (2002). Preface to Learning and Teaching Styles In Engineering Education 1988. Journal of Engineering Education Vol. 78 No. (7), 674 - 681 Retrieved 19th March 2009.

Gordon, D. (2009). Smart Classroom Technologies for Digital Natives. Interviewed by. C. O'Driscoll. Dublin Institute of Technology, Ireland. (13th January 2009).

Harvey, J. (2009). Interactive Classrooms in DIT. Interviewed by. C. O'Driscoll. Dublin Institute of Technology, Ireland. (26th March 2009).

Hsi, S. (2002). The Electronic Guidebook: A Study of User Experiences using Mobile Web Content in a Museum Setting. Proceedings of IEEE International Workshop on Mobile and Wireless Technologies in Education, WMTE, pp 48-54.

Kellegher, J. (2009). Reviewing Smart Classroom Technologies. Interviewed by. C. O'Driscoll. Dublin Institute of Technology, Ireland. (12th January 2009).

Long, S., Aust, D., Abowd, G. and Atkeson, C. (1996). Cyberguide: prototyping contextaware mobile applications. Conference companion on Human factors in computing systems: common ground. Vancouver, British Columbia, Canada, ACM.

Markham, T., Mergendoller, J., Larmer, J. and Ravitz, J. (2003). Project Based Learning Handbook, Buck Institute of Education. September 2003.

Mazur, E. (1997). Peer Instruction: A User's Manual, Prentice Hall, Upper Saddle River, NJ, 1997.

NIST. (2009). NIST Smart Space Project. Retrieved 27th March 2009, from http://www.nist.gov/smartspace/.

Prensky, M. (2001a). Digital Natives, Digital Immigrants. On the Horizon Vol. 9, No.(5). 5, October 2001, MCB University Press.

Prensky, M. (2001b). Digital Natives, Digital Immigrants. Part II : Do They Really Think Differently? On the Horizon Vol. 9, No.(6). 6, December 2001, MCB University Press.

Prensky, M. (2008). Backup Education? Too many teachers see education as preparing kids for the past, not the future. Educational Technology Vol. 48, No.(1). Jan-Feb 2008,

Promethean. (2009). Promethean Interactive Whiteboards. Retrieved 26th March 2009, from http://www.prometheanireland.com/.

Quizdom. (2009). Interactive Classroom Voting SystemWhiteboards. Retrieved 27th March 2009, from http://www.qwizdom.co.uk.

Robles, E., Sukumaran, A., Rickertsen, K. and Nass, C. (2006). Being watched or being special: how I learned to stop worrying and love being monitored, surveilled, and 
assessed. Proceedings of the SIGCHI conference on Human Factors in computing

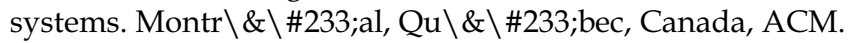

Roche, F. (2009). Interactive Whiteboards for Primary Schools. Interviewed by. C. O'Driscoll. Dublin Institute of Technology, Ireland. (27th March 2009).

Russell, D. M., Streitz, N. A. and Winograd, T. (2005). Building disappearing computers. Communications of the ACM Vol. 48, No.(3), 42-48. ACM. 0001-0782.

Schilit, B., Adams, N. and Want, R. (1994). Context-aware computing applications. Proceedings of Workshop on Mobile Computing Systems and Applications, Proceedings., 85.

Schilit, B. N. and Theimer, M. M. (1994). Disseminating active map information to mobile hosts. Network, IEEE Vol. 8, No.(5), 22.

Shi, Y., Xie, W., Xu, G., Shi, R., Chen, E., Mao, Y. and Liu, F. (2003). The smart classroom: merging technologies for seamless tele-education. Pervasive Computing Vol. 2, No.(2), 47-55. IEEE.

SMARTBoard. (2009). SMART Board Interactive Whiteboards. Retrieved 26th March 2009, from http://www.smarttech.com/Products/smartboard/index.asp.

Snow, C., Pullen, J. M. and McAndrews, P. (2005). Network EducationWare: an open-source web-based system for synchronous distance education. Education, IEEE Transactions on Vol. 48, No.(4), 705-712.

Streitz, N. and Nixon, P. (2005). Introduction to The Disappearing Computer. Communications of the ACM Vol. 48, No.(3), 32-35. ACM. 0001-0782.

Suo, Y., Miyata, N., Morikawa, H., Ishida, T. and Shi, Y. (2008). Open Smart Classroom : Extensible and Scalable Learning System in Smart Space using Web Service Technology. IEEE Transactions on Knowledge and Data Engineering Vol. (Accepted for publication in June 2008 for future issue) Available via IEEE eXplore. Accessed 16th March 2009.

Want, R., Hopper, A., Falcao, V. and Gibbons, J. (1992). The active badge location system. ACM Transactions on Information Systems Vol. 10, No.(1), 91-102. ACM. 10468188.

Weiser, M. (1991). The computer for the 21st century. Scientific American Vol. 265, No.(3), 94-104. September 1991 (Reprinted in Communications of ACM July 1993. Vol.3 No. (3): p. 3-11),

Weiser, M. (1993). Some computer science issues in ubiquitous computing. Communications of the ACM Vol. 36, No.(7), 75-84. ACM. 0001-0782. 


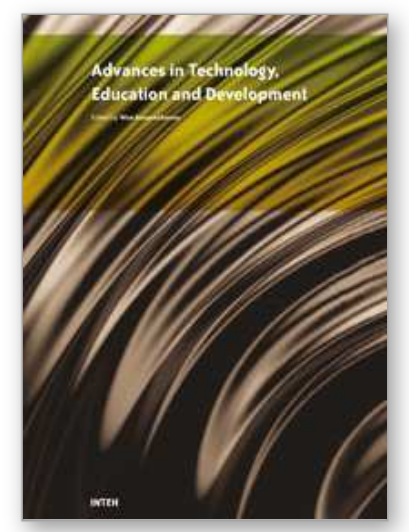

\section{Advances in Technology, Education and Development \\ Edited by Wim Kouwenhoven}

ISBN 978-953-307-011-7

Hard cover, 474 pages

Publisher InTech

Published online 01, October, 2009

Published in print edition October, 2009

From 3rd to 5th March 2008 the International Association of Technology, Education and Development organised its International Technology, Education and Development Conference in Valencia, Spain. Over a hundred papers were presented by participants from a great variety of countries. Summarising, this book provides a kaleidoscopic view of work that is done, all over the world in (higher) education, characterised by the key words 'Education" and 'Development'. I wish the reader an enlightening experience.

\section{How to reference}

In order to correctly reference this scholarly work, feel free to copy and paste the following:

Ciaran O'Driscoll (2009). Smart Classroom Technology, Advances in Technology, Education and Development, Wim Kouwenhoven (Ed.), ISBN: 978-953-307-011-7, InTech, Available from: http://www.intechopen.com/books/advances-in-technology-education-and-development/smart-classroomtechnology

\section{INTECH}

open science | open minds

\section{InTech Europe}

University Campus STeP Ri Slavka Krautzeka 83/A 51000 Rijeka, Croatia Phone: +385 (51) 770447

Fax: +385 (51) 686166 www.intechopen.com

\section{InTech China}

Unit 405, Office Block, Hotel Equatorial Shanghai No.65, Yan An Road (West), Shanghai, 200040, China 中国上海市延安西路65号上海国际贵都大饭店办公楼405单元 Phone: +86-21-62489820

Fax: +86-21-62489821 
(C) 2009 The Author(s). Licensee IntechOpen. This chapter is distributed under the terms of the Creative Commons Attribution-NonCommercial-ShareAlike-3.0 License, which permits use, distribution and reproduction for non-commercial purposes, provided the original is properly cited and derivative works building on this content are distributed under the same license. 